\title{
Knockdown of Dyslexia-Gene Dcdc2 Interferes with Speech Sound Discrimination in Continuous Streams
}

\author{
DTracy Michelle Centanni, ${ }^{1,2}$ Anne B. Booker, ${ }^{3}$ Fuyi Chen, ${ }^{3}{ }^{\circledR}$ Andrew M. Sloan, ${ }^{1}$ Ryan S. Carraway, ${ }^{1}$ \\ Robert L. Rennaker, ${ }^{1}$ Joseph J. LoTurco, ${ }^{3}$ and Michael P. Kilgard ${ }^{1}$ \\ ${ }^{1}$ University of Texas at Dallas, Richardson, Texas 75080, ${ }^{2}$ Massachusetts Institute of Technology, Cambridge, Massachusetts 02139 , and ${ }^{3}$ University of \\ Connecticut, Storrs, Connecticut 06269
}

Dyslexia is the most common developmental language disorder and is marked by deficits in reading and phonological awareness. One theory of dyslexia suggests that the phonological awareness deficit is due to abnormal auditory processing of speech sounds. Variants in $D C D C 2$ and several other neural migration genes are associated with dyslexia and may contribute to auditory processing deficits. In the current study, we tested the hypothesis that RNAi suppression of $D c d c 2$ in rats causes abnormal cortical responses to sound and impaired speech sound discrimination. In the current study, rats were subjected in utero to RNA interference targeting of the gene $D c d c 2$ or a scrambled sequence. Primary auditory cortex (A1) responses were acquired from 11 rats ( 5 with $D c d c 2 \mathrm{RNAi}$; DC - ) before any behavioral training. A separate group of 8 rats $(3 \mathrm{DC}-$ ) were trained on a variety of speech sound discrimination tasks, and auditory cortex responses were acquired following training. $D c d c 2$ RNAi nearly eliminated the ability of rats to identify specific speech sounds from a continuous train of speech sounds but did not impair performance during discrimination of isolated speech sounds. The neural responses to speech sounds in $\mathrm{A} 1$ were not degraded as a function of presentation rate before training. These results suggest that $\mathrm{A} 1$ is not directly involved in the impaired speech discrimination caused by $D c d c 2$ RNAi. This result contrasts earlier results using Kiaa0319 RNAi and suggests that different dyslexia genes may cause different deficits in the speech processing circuitry, which may explain differential responses to therapy.

Key words: access; candidate gene; cortex; perception; reading; representation

Significance Statement

Although dyslexia is diagnosed through reading difficulty, there is a great deal of variation in the phenotypes of these individuals. The underlying neural and genetic mechanisms causing these differences are still widely debated. In the current study, we demonstrate that suppression of a candidate-dyslexia gene causes deficits on tasks of rapid stimulus processing. These animals also exhibited abnormal neural plasticity after training, which may be a mechanism for why some children with dyslexia do not respond to intervention. These results are in stark contrast to our previous work with a different candidate gene, which caused a different set of deficits. Our results shed some light on possible neural and genetic mechanisms causing heterogeneity in the dyslexic population.

\section{Introduction}

Dyslexia is the most common developmental communication disorder and is diagnosed by poor reading scores in the presence of normal, nonverbal intelligence (Shaywitz, 1998; Catts et al.,

\footnotetext{
Received Nov. 23, 2015; revised March 25, 2016; accepted March 29, 2016.

Author contributions: T.M.C., R.L.R., and M.P.K. designed research; T.M.C., A.B.B., F.C., A.M.S., and R.S.C. performed research; F.C., R.L.R., and J.J.L. contributed unpublished reagents/analytic tools; T.M.C., A.B.B., F.C., A.M.S., J.J.L., and M.P.K. analyzed data; T.M.C. and M.P.K. wrote the paper.

This work was supported by National Institute of Deafness and Other Communication Disorders at the National Institutes of Health Grant R01DC010433. We thank Kwok Im, Nicole Moreno, Kimiya Rahebi, Elizabeth Hancik, Michael Borland, Elizabeth Buell, Melissa Fink, and Ryan Carraway for help with microelectrode recordings; Navid Khodaparast, Linda Baxter, Kim Trull, and Nick Wasko for help with histology; and Crystal Engineer for help with data interpretation and comments and suggestions on earlier versions of this manuscript.

The authors declare no competing financial interests.
}

2005; Peterson and Pennington, 2012). Individuals with dyslexia often have deficits in tasks involving phoneme deletion or switching, word rhyming, and nonword reading (Schulte-Körne, 2010; Vandermosten et al., 2010; Farquharson et al., 2014). Impaired phonological awareness may make reading more difficult because the mapping from phonemes to graphemes is compromised (Temple et al., 2000; Hornickel and Kraus, 2013; Centanni et al., 2014a). Phonological interventions are helpful but do not benefit all children (Simos et al., 2007; Odegard et al., 2008; Davis

Correspondence should be addressed to Dr. Tracy Michelle Centanni, Massachusetts Institute of Technology, 43 Vassar Street, 46-4037C, Cambridge, MA 02139. E-mail: tmcentanni@gmail.com.

DOI:10.1523/JNEUROSCI.4202-15.2016

Copyright $\odot 2016$ the authors $\quad 0270-6474 / 16 / 364895-12 \$ 15.00 / 0$ 
et al., 2011). Genetic factors may contribute to the inconsistency in intervention success rates (Eckert, 2004; Galaburda et al., 2006; Odegard et al., 2008; Newbury et al., 2011; Pinel et al., 2012).

Dyslexia is highly heritable with a $68 \%$ concordance rate among monozygotic twins (DeFries et al., 1987; Pennington et al., 1991). There are currently four candidate-dyslexia genes identified by replicated studies: DCDC2, KIAA0319, DYX1C1, and $R O B O 1$. These genes are involved in neural migration, and suppression of any of these genes leads to abnormal cortical structure in rodents (Galaburda et al., 2006; Bai et al., 2008; Szalkowski et al., 2013). However, many individuals with dyslexia have variants in multiple genes, which makes it difficult to understand the role of specific mutations on the underlying mechanisms of the disorder. A better understanding of the role each of these genes plays in causing the phenotype of dyslexia may lead to more effective early diagnostic tools and might prove useful for selecting the most effective intervention for each child.

Similar to KIAA0319, variants in DCDC2 have been linked with reading and spelling impairments in humans with dyslexia and poor phonological awareness (Scerri et al., 2011; Marino et al., 2012). Distinctly, variants in DCDC2 have been linked to poor serial visual search in humans (Sireteanu et al., 2008; Vidyasagar, 2013), whereas KIAA0319 variants have no known association with visual processing deficits. In the knock-out mouse, elimination of Dcdc2 protein corresponds with increases in the NMDA receptor subunit Grin2B, which possibly contributes to increased excitability in cortical neurons (Truong et al., 2014). Increased excitability may lead to difficulty maintaining focused attention on a long stream of distractors, similar to difficulties observed in humans with dyslexia completing serial visual search tasks (Lind et al., 2010; Schulte-Körne and Bruder, 2010; Danelli et al., 2013; Gori et al., 2015). In addition, microdeletions in this gene have recently been linked to visual motion deficits in some individuals with dyslexia (Cicchini et al., 2015). It is therefore unknown whether the gene $D C D C 2$ contributes to auditory processing deficits or whether this gene contributes solely to grapheme recognition deficits.

Rats are a useful model for speech sound processing and have been used to evaluate the correlation between brain responses and behavior in a variety of language and communication disorder models (Centanni et al., 2014a,b; C. T. Engineer et al., 2014a, c, 2015; Reed et al., 2014). Suppression of another candidatedyslexia gene, Kiaa0319, causes inconsistent neural firing in primary auditory cortex (A1) in response to auditory stimuli (Centanni et al., 2014a) and impairs behavioral performance on phoneme discrimination tasks (Centanni et al., 2014b). Knockout of $D c d c 2$, however, causes impaired performance on a spatial maze task (Wang et al., 2011), which requires multitasking and attention switching. Increased neural excitability is likely to contribute to difficulty in navigating an environment with many distractors.

In the current study, we acquired A1 microelectrode recordings in rats with in utero suppression of $D c d c 2$. We also evaluated behavioral performance on a variety of speech sound discrimination tasks and tested whether such training causes cortical plasticity. These studies were designed to test the hypotheses that reduced expression of the dyslexia-candidate gene $D c d c 2$ (1) impairs behavior and (2) alters neural responses to auditory stimuli, including speech sound streams.

\section{Materials and Methods}

Animals. Subjects were Wistar rats that were 3-6 months old at the time of study. All rats used were subjected as embryos to in utero electropora- tion targeting lateral regions of neocortex that included the auditory cortex by methods described previously (Bai et al., 2003, 2008; Threlkeld et al., 2007; Burbridge et al., 2008). The animals were transfected with either an shRNA against $D c d c 2$, which can decrease the Dcdc2 protein expression in cell culture (Tarkar and J.J.L., unpublished observation) and cause migration delay in embryonic neocortex that can be rescued by expression of exogenous Dcdc2 (Burbridge et al., 2008) or a scrambled control sequence. To ensure differences due to surgical procedure were minimized, littermate controls were used. Control transfection animals received a scrambled sequence control of $D c d c 2$ shRNA, also previously used, that contained 6 bases in the sequence scrambled to render the shRNA inactive in terms of reducing Dcdc2 expression (Burbridge et al., 2008). Dcdc2 shRNA and scrambled shRNA constructs were injected at a concentration of $1.0 \mu \mathrm{g} / \mu \mathrm{l}$. pB-GFP was cotransfected with the effective shRNA construct, and $\mathrm{pB}$-mRFP was cotransfected with the scrambled $D c d c 2$ shRNA control construct to identify the experimental condition in postexperimental histological analysis. Electroporation paddles were placed in a horizontal plane, and voltage pulses were discharged across the cerebrum in both polarities to achieve bilateral transfections. The day of transfection and the orientation of the paddles were to ensure targeting of layer $2 / 3$ pyramidal cells in bilateral auditory cortex.

Experimenters remained blind to the experimental status of each subject throughout data collection and analysis. Following data collection, each subject was perfused transcardially with $250 \mathrm{ml}$ of $0.1 \mathrm{M}$ phosphate buffer solution with $0.02 \%$ heparin, followed by $500 \mathrm{ml}$ of $4 \%$ formalin solution in $0.1 \mathrm{~m}$ phosphate buffer. Sections were taken at $80 \mu \mathrm{m}$ intervals and analyzed under a confocal microscope (Zeiss) to identify the experimental status of each subject (green florescent protein marked experimental subjects and red florescent protein marked control littermates). The location and density of affected cells were marked on standard images by an experienced researcher who was blinded to the experiential status of the animal (e.g., DC - or control). Custom MATLAB programming (The MathWorks) was used to count the colored pixels on each slice. This number was then normalized and served as a unit of the amount of transfection.

All animal protocols were approved by the University of Connecticut and University of Texas at Dallas Institutional Animal Care and Use Committees.

Behavioral paradigm. We trained 8 rats to discriminate a target speech sound $(/ \mathrm{dad} /)$ in 4 different contexts. Of these rats, 3 received RNAi of $\operatorname{Dcdc} 2$ (2 males; DC-) and 5 received scrambled RNAi and served as controls ( 1 male). This ratio of DC - to control animals was due to the fact that we were unaware of each animal's experimental status during training. Because these were littermate controls, we trained the full litter and determined whether each rat was DC- or control following the study. The behavior tasks we tested are described in detail previously and are identical to those used in our previous studies of Kiaa0319 RNAi in rats (Centanni et al., 2014a,b). Briefly, rats were trained to respond to a target sound /dad/ using either a lever press or by withdrawal from an infrared-monitored nose poke. Rats were then trained to wait for the presentation of a target sound before making a response. Once rats reached a d' of $\geq 1.5$ for 10 sessions, they were tested for a minimum of 20 sessions on each of four discrimination tasks (Green and Swets, 1966).

The isolated speech task consisted of a go-no go paradigm in which rats were trained to press a lever in response to the target sound and to reject each of seven distractors: /dad/ versus /bad/, /gad/, /sad/, /tad/, /dud/, /deed/, /dood/ (C. T. Engineer et al., 2008). Rats were rewarded with a food pellet if they pressed within $3 \mathrm{~s}(\mathrm{~s})$ of the target and punished with a $6 \mathrm{~s}$ time out for false alarms. The speech-in-noise task used the same stimuli with the addition of four levels $(0,48,60,72 \mathrm{~dB}$ SPL) of continuous speech-shaped background noise (Shetake et al., 2011). This task was chosen because of the known difficulty of children with dyslexia to discriminate speech sounds in background noise (Ziegler et al., 2009). The truncated speech task was identical to the go-no go discrimination task, except that only the first $40 \mathrm{~ms}$ of each speech sound was presented (Porter et al., 2011). This task was chosen to examine discrimination of individual phonemes, which is a core deficit in dyslexia (Ramus, 2014). These three tasks used a lever press response mechanism. The speech stream task used an infrared-monitored nose poke and involved the 
presentation of a random sequence of distractor sounds (/bad/, /gad/, $/ \mathrm{sad} /, / \mathrm{tad} /)$, with the target sound $(/ \mathrm{dad} /)$ inserted randomly between 2 and $7 \mathrm{~s}$ from the start of the trial. Sounds were only delivered while the rat's nose was inside the nose poke and were presented at six different speeds between 2 and 20 syllables per second (Centanni et al., 2014c). Blocks of 20 trials were presented at the same presentation rate, and the rate of each block was randomized. Rats were rewarded with a food pellet if they removed their nose within $500 \mathrm{~ms}$ of the target and punished with a $6 \mathrm{~s}$ time out for false alarms. Percentage correct is reported as the average hit rate minus the false alarm rate for each task.

Anesthetized recordings. Multiunit recordings were acquired from auditory cortex of all rats: 11 without any behavioral training $(N=5$ DC $-/ 2$ males and $N=6$ controls $/ 3$ males) and 7 following behavioral training $(N=3 \mathrm{DC}-/ 2$ males and $N=4$ controls $/ 1$ male; one trained control rat died during surgery). The recording procedure is explained in detail previously (Centanni et al., 2013). In brief, animals were anesthetized with pentobarbital $(50 \mathrm{mg} / \mathrm{kg})$ and given supplemental dilute pentobarbital $(8 \mathrm{mg} / \mathrm{ml})$ as needed to maintain areflexia, along with fluids to prevent dehydration. Auditory cortex was exposed via craniotomy and durotomy. Four Parylene-coated tungsten microelectrodes (1-2 M $\Omega$ ) were simultaneously lowered to layer IV of right auditory cortex $(\sim 600-$ $800 \mu \mathrm{m})$.

Brief tones were presented at 90 randomly interleaved frequencies $(1-48 \mathrm{kHz})$ at 16 intensities $(0-75 \mathrm{~dB} \mathrm{SPL})$ to determine the characteristic frequency of each site. Tones had $5 \mathrm{~ms}$ cosine squared ramps, and their total duration was $25 \mathrm{~ms}$. Auditory fields were identified by characteristic frequency, latency, and direction of tonotopic organization (Polley et al., 2007; Centanni et al., 2013). Additional stimuli were randomly interleaved and presented at 20 repeats per recording site. Broadband noise was presented in trains of six 25 -ms-long bursts at four different presentation rates $(4,7,10$, and $12.5 \mathrm{~Hz})$. Broadband stimuli contained evenly distributed frequencies between 1 and $32 \mathrm{kHz}$. We also presented 8 English consonant-vowel-consonant speech sounds (/bad/, /dad/, $/ \mathrm{gad} /$, /sad/, /tad/, /dud/, /deed/, and /dood/) previously tested in our laboratory (C. T. Engineer et al., 2008; Centanni et al., 2013). Sounds were shifted up 1 octave using the STRAIGHT vocoder to better match the rat hearing range (Kawahara, 1997). Each sound was calibrated so that the most intense $50 \mathrm{~ms}$ of the stimulus length was $60 \mathrm{~dB}$ SPL. All sounds were presented $\sim 10 \mathrm{~cm}$ from the left ear of the rat.

In behaviorally naive controls, we acquired $258 \mathrm{~A} 1$ recording sites. In behaviorally naive DC - rats, we acquired 229 recording sites from A1. In behaviorally trained controls, we acquired 169 sites and $127 \mathrm{~A} 1$ sites in behaviorally trained $\mathrm{DC}-$ rats.

Analysis of neural recordings. To identify the location of A1, an experienced observer, blinded to the location of each recording site, manually analyzed multiunit recording sites to select the characteristic frequency of each site, as well as to obtain bandwidth, latency, peak firing, and end of peak response information. Basic firing properties were calculated in response to tones. Firing latency is defined as the point in time (ms) that average firing rate (across all repeats) first exceeds 2 SDs above the spontaneous firing rate, threshold is defined as the lowest intensity that evoked a response from the multiunit site, and bandwidths were calculated at 10,20,30, and $40 \mathrm{~dB}$ above threshold and defined as the range of frequencies that evoked responses at the current intensity. In response to broadband click trains, normalized spike rate (number of spikes evoked by bursts $2-6$, normalized by the number of spikes to the first burst) and vector strength (VS) were calculated. This metric measures the degree of synchronization between action potentials and repeated sounds. Mean VS is calculated with the following formula:

$$
V S=\frac{1}{n} \sqrt{x^{2}+y^{2}} ; x=\sum_{i=1}^{n} \cos \theta_{i} ; y=\sum_{i=1}^{n} \sin \theta_{i} \theta_{i}=2 \pi \frac{t_{i}}{T}
$$

where $n$ is the total number of action potentials, $t_{i}$ is the time of occurrence of the $i$ th action potential, and $T$ is the interstimulus interval. Perfect synchronization would result in a value of 1 , whereas no synchronization would result in a value of 0 . To investigate the reliability of response latency to repetitive stimuli, we calculated the time to peak latency within the first $80 \mathrm{~ms}$ (the shortest interpulse interval tested) of the first pulse at $4 \mathrm{~Hz}$ and averaged across multiunit sites. The variability (variance) in this measure across trials was compared across DC- and controls.

We used two different classifier algorithms to evaluate single trial neural responses to speech sounds. For isolated speech sounds, we used a nearest neighbor classifier (Foffani and Moxon, 2004; Centanni et al., 2013, 2014a). For the continuous speech sounds, we used a sliding window classifier (Centanni et al., 2014c). We chose these methods because our earlier studies showed that the performance of these classifiers is highly correlated with rat behavioral discrimination in isolated and speech stream discrimination tasks, respectively (C. T. Engineer et al., 2008; Shetake et al., 2011; Ranasinghe et al., 2012; Centanni et al., 2013, 2014b). Both classifiers used Euclidean distance to compare single trial peristimulus time histograms (PSTHs) to the average PSTH evoked by 19 repeats each of the different stimuli. Previous work has demonstrated that, although the brain relies on temporal precision to encode consonant sounds, the brain likely relies on response intensity over a longer time period to encode different vowel sounds (Perez et al., 2013). Therefore, for consonants, activity was binned using $1 \mathrm{~ms}$ bins over a $40 \mathrm{~ms}$ window to encompass the spike timing precision present in the initial consonant, whereas vowel activity was analyzed across a single $400 \mathrm{~ms}$ bin so that spike count information was preserved. The classifier then compared the response of each single trial with the average activity template (PSTH) evoked by all repeats of each of the speech stimuli presented. The current trial being considered was not included in the PSTH template to avoid artifact. For isolated speech sounds, the classifier attempted to identify the stimulus that evoked the current single trial activity pattern by selecting the template that was most similar to the single trial in units of Euclidean distance (ED). For continuous speech sounds, the classifier evaluated similarity within a sliding, $40 \mathrm{~ms}$ window. Following analysis of the entire sequence (in $40 \mathrm{~ms}$, sliding windows), the classifier guessed the target sound's location based on the "best fit" to the template. ED was calculated using the following formula:

$$
\text { Euclidean Distance }=\sqrt{\sum_{i=1}^{\text {Fsites }} \sum_{j=1}^{\# b i n s}\left(X_{i j}-Y_{i j}\right)^{2}}
$$

where $\#_{\text {sites }}$ is each recording site and $\#_{\text {bins }}$ is each of $401 \mathrm{~ms}$ bins being compared between activity evoked by speech sound $X$ versus speech sound $Y$. For vowel sounds, the classifier counted the number of action potentials over the single $400 \mathrm{~ms}$ bin and compared the single trial response with the two PSTH templates.

Statistics. We used multiway ANOVAs and $t$ tests for all pairwise comparisons. To determine differences across multiple days of testing or across multiple groups, an $\alpha$ of 0.01 was used to correct for multiple comparisons.

\section{Results \\ Transfection efficacy}

Previous experiments using this RNAi technique report that generally $<5 \%$ of cells (as analyzed after birth) are affected by the transfection (Threlkeld et al., 2007; Centanni et al., 2014a,b). Despite this low number of surviving affected cells, RNAi of other candidate-dyslexia genes are well known to cause anatomical, neural firing, and behavioral impairments (Threlkeld et al., 2007; Szalkowski et al., 2012, 2013; Centanni et al., 2014a,b). There was no significant difference in the amount of transfection that occurred between DC- rats and control rats using a normalized pixel count of the affected area (see Materials and Methods; $0.81 \pm 0.1$ in $\mathrm{DC}-$ rats vs $0.78 \pm 0.1$ in control rats; unpaired $t$ test, $p=0.76)$. The efficacy of the RNAi in the current study was not statistically different from that used in our previous studies of RNAi of Kiaa0319 (unpaired $t$ test; $p=0.77$ ). This result suggests that the process was not more or less effective when a gene was targeted compared using a scramble control plasmid. We did not see any evidence of other effects of the RNAi procedure, such as 
A

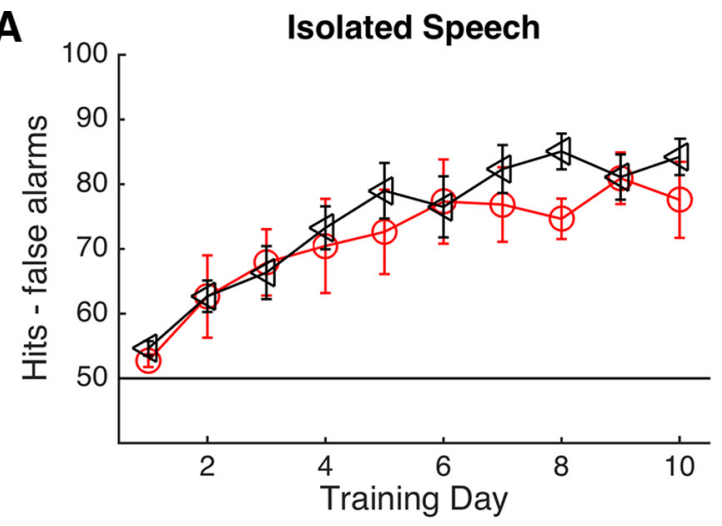

C

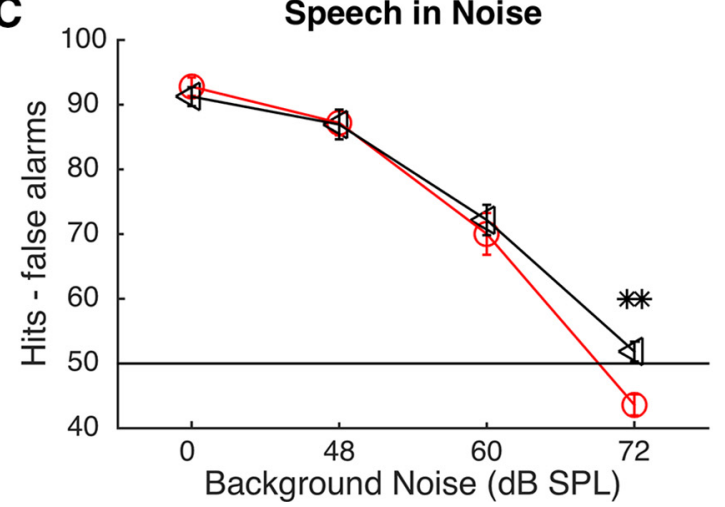

B

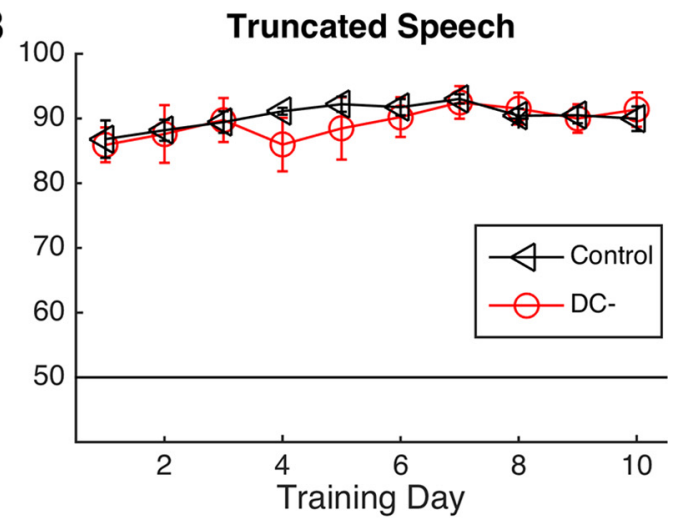

D

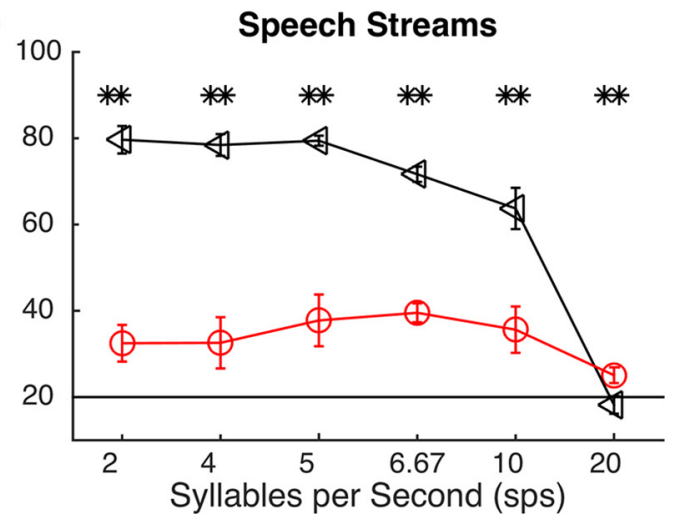

Figure 1. Behavioral results on speech discrimination tasks in trained control and trained $D C-$ rats. Error bars represent $S E M$. $A, B$, Both trained $D C-$ and trained control rats were able to accurately discriminate between isolated speech sounds and truncated speech sounds in quiet conditions. $\boldsymbol{C}$, Both trained groups were able to accurately discriminate speech sounds in background noise that was as loud as the signal ( $60 \mathrm{~dB}$ SPL). Chance performance on isolated speech, truncated speech, and speech-in-noise tasks was $50 \%$ because half of stimuli presented were target sounds. $D$, Trained $D C$ - rats were significantly impaired on the speech stream task. ${ }^{* *} p<0.01$. Chance performance for the speech stream task was $20 \%$ because there were many more nontargets than targets in the continuous speech stream.

ectopia at the injection site. This result supports previous work demonstrating the effectiveness of this technique (Bai et al., 2003; Burbridge et al., 2008; Centanni et al., 2014a,b).

\section{Behavioral performance is only impaired during speech stream discrimination}

A group of 8 rats ( 5 control, 3 DC-) were trained on four speech sound discrimination tasks. All rats were able to successfully learn to press a lever in response to the target sound $/ \mathrm{dad} /$. There was no difference in the amount of training time needed to reach a $\mathrm{d}^{\prime}$ $>1.5$ for two consecutive sessions correct across groups $(8 \pm$ $2.3 \mathrm{~d}$ for $\mathrm{DC}-$ rats vs $7 \pm 1.5 \mathrm{~d}$ for control rats; unpaired $t$ test, $p=0.72$ ). This result suggests that suppression of the gene $D c d c 2$ does not affect basic task learning. When tested on an isolated speech task (press the lever to / dad/ and ignore /bad/, /gad/, /sad/, $/ \mathrm{tad} /$, /dud/, /deed/, and /dood/), there was no group effect (repeated-measures ANOVA, $F_{(1,48)}=0.2, p=0.67$ ), although both groups improved over time (repeated-measures ANOVA, $F_{(8,48)}=24.95, p=0.0001$; Fig. $\left.1 A\right)$.

There were no significant differences in either vowel discrimination (/dad/ vs /dud/, /deed/, and /dood/) or consonant discrimination (/dad/ vs /bad/, /gad/, /sad/, /tad/) across groups (all unpaired $t$ tests; $p>0.06)$. There were also no differences in reaction time on this task $(1372.7 \pm 170.1 \mathrm{~ms}$ in $\mathrm{DC}-$ rats vs $1469.9 \pm 108.8 \mathrm{~ms}$ in controls; unpaired $t$ test, $p=0.53)$. In the second task we tested, only the first $40 \mathrm{~ms}$ of the stimulus was presented, which contained the consonant information and the beginning of the transition to the vowel. This task was selected because this task was previously shown to be affected by Kiaa0319
RNAi as well as by brain damage (Porter et al., 2011; Centanni et al., 2014b). Across $10 \mathrm{~d}$ of testing on this task, we saw no significant group differences $(p=0.18$; Fig. $1 B)$. There were significant group differences in performance across noise levels but not across groups on the speech-in-noise task. During this task, rats performed the same discrimination task as the isolated speech task, but with each of four levels of speech-shaped noise in the background (Shetake et al., 2011). Discrimination performance dropped by $23 \%$ in the $60 \mathrm{~dB}$ noise ( $0 \mathrm{~dB}$ SNR) compared with the $0 \mathrm{~dB}$ noise condition in $\mathrm{DC}-$ rats and by $19 \%$ in control rats (unpaired $t$ tests of performance at $0 \mathrm{~dB}$ compared with performance at $60 \mathrm{~dB}, p=0.0001$; Fig. $1 C)$. Neither group was able to reliably discriminate in $72 \mathrm{~dB}$ noise $(-12 \mathrm{~dB}$ SNR; $43.6 \pm 1.6 \%$ correct in DC - rats vs $51.9 \pm 1.5 \%$ correct in controls; unpaired $t$ tests for performance at $72 \mathrm{~dB}$ compared with chance performance of $50 \%$, all $p$ values $<0.01$; Fig. $1 C$ ). Collectively, these results suggest that $D c d c 2$ RNAi does not impair the ability of rats to distinguish between speech sounds presented in isolation (sounds presented at $0.16 \mathrm{~Hz}$ ).

$D c d c 2$ RNAi nearly eliminated the ability of rats to distinguish between specific speech sounds when presented at greater speeds. The target and distracter sounds were the same as in the isolated speech task; but for the speech stream task, the target sound was embedded in a continuous stream of nontarget speech sounds. The speech sounds were presented at a variety of presentation rates from 2 to 20 syllables per second (Centanni et al., 2014c). Average performance in control rats over the final $5 \mathrm{~d}$ of this task was $65.2 \pm 10.7 \%$ compared with $33.8 \pm 2.3 \%$ in $\mathrm{DC}-$ rats (unpaired $t$ tests, $p<0.001$; Fig. 1D). The impairment seen in the 
A

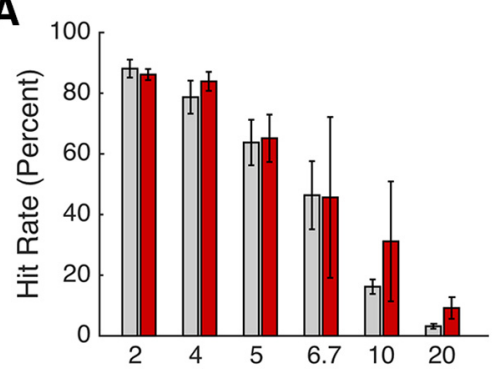

C

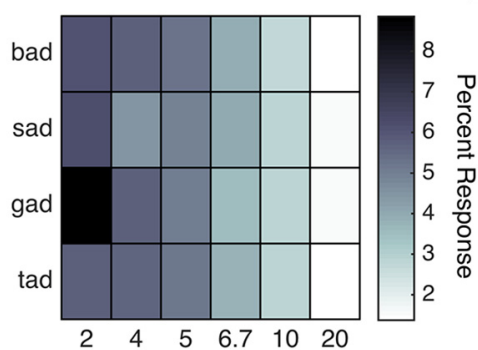

Syllables per Second (sps)
B

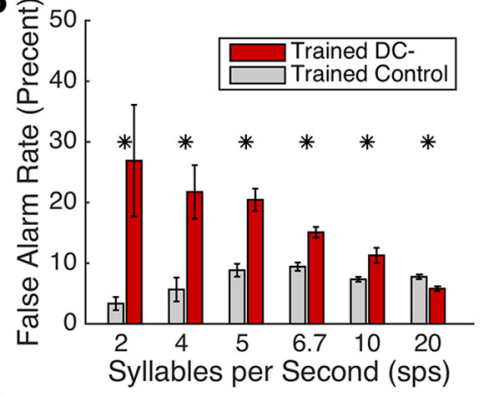

D

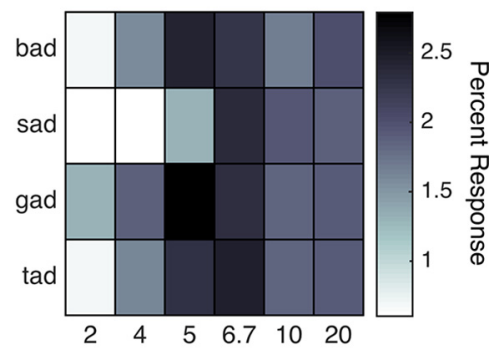

Syllables per Second (sps)

Figure 2. Hit and false alarms for both trained groups during the speech stream discrimination task. Error bars represent SEM. $A$, Trained $D C$ - rats did not differ in the amount of correct lever presses at any presentation rate compared with trained control rats. $\boldsymbol{B}$, Trained $D C$ - rats had significantly more false alarms than trained control rats at every presentation rate. ${ }^{*} p<0.05 . C, D$, Confusion matrix for response rates to distracter sounds by trained $D C$ - rats $(\boldsymbol{C})$ and trained control rats $(\boldsymbol{D})$. Both groups of rats responded to all distracter sounds at similar levels within each presentation rate. $D C$ - rats reduced their false alarm rates as presentation rate increased, whereas control rats increased their false alarm rates as presentation rate increased. Importantly, these panels are presented at different scales to show the interstimulus differences within groups.

DC - rats was due not to a significant reduction in correct responses (Fig. 2A), but to significantly more false alarms at every rate (unpaired $t$ tests, $p<0.03$; Fig. $2 B$ ). To determine whether a specific sound was causing specific difficulty for the $\mathrm{DC}$ - rats, we counted the number of incorrect responses to the distractor sounds at each presentation rate for trained DC- rats (Fig. 2C) and for trained control rats (Fig. 2D). There was no main effect of distractor on response rates within groups (repeated-measures ANOVA, $\left.F_{(1,3)}=2.62, p=0.07\right)$, although, as expected, there was a main effect of group $\left(F_{(1,1)}=9.07, p=0.01\right)$. We also observed an interaction between group and presentation rate: at faster presentation rates, DC - rats had fewer false alarm rates than at slower speeds, but control rats had more false alarms at slower speeds $\left(F_{(1,5)}=20.77, p<0.0001\right)$. Because of our small sample size, we were unable to statistically measure correlations between RNAi efficacy and behavior to determine whether the amount of protein in the brain directly predicted behavioral performance (Pearson's $r=0.77, p=0.44$ ).

Greater false alarm rates could be due to increased excitability in the brain, leading to faster reaction times. To determine whether suppression of $D c d c 2$ increased excitability, we compared reaction times across groups. Trained DC - rats responded significantly faster than trained control rats at 2 of the 6 speeds (121 ms faster at $2 \mathrm{sps} ; p=0.02$ and $83 \mathrm{~ms}$ faster at $10 \mathrm{sps} ; p=$ $0.003)$. Previous work in humans with dyslexia has demonstrated that serial search tasks, similar to our speech stream task, often result in shorter reaction times in individuals with dyslexia (Sireteanu et al., 2008). It is also possible that this gene is playing a role in increasing hyperactivity, as DCDC2 has also been linked with attention deficit hyperactivity disorder in humans (Scerri et al., 2011).
Neural responses to nonspeech sounds are altered in untrained $\mathrm{DC}-$ rats

Several basic firing properties were significantly different in rats with $D c d c 2$ knockdown compared with controls, which may contribute to the observed behavioral impairments. DC - rats had a shorter onset latency $(19.7 \pm 0.4 \mathrm{~ms}$ vs $22.3 \pm 0.7 \mathrm{~ms}$; unpaired $t$ test; $p=0.003)$ and higher spontaneous firing $(14.6 \pm 0.6$ spikes vs $12.6 \pm 0.6$ spikes; unpaired $t$ test; $p=$ 0.03 ) compared with control rats (Fig. $3 C, D$; Table 1). This result supports the hypothesis that suppression of $D c d c 2$ increases excitability in the brain. A1 neurons in $\mathrm{DC}$ - rats were better able to synchronize A1 activity to broadband noise bursts at 3 of the 4 speeds tested (all $p$ values $<0.001$; Fig. $3 E$ ). Unlike our previous report on the dyslexia-candidate gene Kiaa0319 (Centanni et al., 2014a), knockdown of $D c d c 2$ did not increase response variability in A1 compared with controls (variance in onset latency; $41.2 \pm$ $2.5 \mathrm{~ms}^{2}$ in DC- rats vs $45.2 \pm 3.6 \mathrm{~ms}^{2}$ in control rats; unpaired $t$ test; $p=0.37$ ).

\section{Neural processing of speech in untrained rats}

To determine whether the cause of the speech stream discrimination deficit was due to increased excitability in neural firing to speech sounds, we evaluated the precision of A1 responses to consonant and vowel stimuli using the raw neural signal as well as a well-documented nearest-neighbor classifier (C. T. Engineer et al., 2008; Centanni et al., 2013; Perez et al., 2013). We evaluated neural responses from behaviorally naive animals $(N=6$ controls and $N=5 \mathrm{DC}-$ rats) to determine the effects of $D c d c 2$ RNAi (Reed et al., 2011; C. T. Engineer et al., 2014b). First, we observed no difference in the number of action potentials driven by isolated speech sounds across groups ( $p>0.10$; Fig. $3 A$ ). Using ED, we then quantified how uniquely consonant sounds were encoded in A1 both across groups and across sounds within groups. $\mathrm{ED}$ is a measure of similarity, and values closer to 0 indicate similar patterns, whereas values closer to 1 indicate unique patterns. Overall, neural responses to consonant sounds were distinct in each group (ED of $0.80 \pm 0.04$ in $D C-A 1$ vs $0.79 \pm 0.04$ in control rats; unpaired $t$ test, $p=0.86$ ). The observation that consonant sounds evoked unique patterns of activity in A1 of both groups supports the high degree of behavioral accuracy at discriminating these sounds.

We next evaluated the ability of a nearest-neighbor classifier to determine stimulus identity. When A1 activity from control rats was used, the classifier achieved $72.1 \pm 1.7 \%$ correct compared with $72.1 \pm 1.8 \%$ correct when using A1 activity from DC - rats to discriminate between consonant pairs (unpaired $t$ test, $p=0.98$; Fig. $4 A$ ). When using neural activity from DCrats, the classifier did not perform significantly worse than controls on the vowel comparison tasks (unpaired $t$ tests, $p>0.05$; Fig. $4 B$ ). We also compared auditory cortex activity over a larger area using the local field potential (LFP) response. The peak-topeak difference in the LFP response did not differ across groups (unpaired $t$ test, $p=0.59$; Fig. $4 C$ ). These responses indicate that 
there is not a large difference in the neural response to speech sounds in isolation after suppression of $D c d c 2$ in rats and that increased excitability in auditory cortex does not interfere with speech sound encoding. This result is in contrast with our previous result in Kiaa0319 knockdown rats, which had significant impairments in Al encoding of both consonant and vowel stimuli (Centanni et al., 2014a).

Although there was no difference in neural encoding of isolated consonant sounds in DC- rats, the rapid presentation of these sounds may have degraded the precision of the $\mathrm{A} 1$ response, as presentation rate is known to affect neural firing (Ahissar et al., 2001; Shetake et al., 2012). To test the hypothesis that rapid presentation degrades the neural response to consonant sounds by magnifying the effect of increased neural excitability, we recorded A1 responses to a sequence of speech sounds (/bad-bad-gad-sad-tad$\mathrm{dad} /)$ presented at each of 6 rates $(2,4,5$, $6.7,10$, and 20 sps). Because of time constraints during neural recordings, we were only able to play a single sequence at each speed, but we have previously shown that speech sound order does not affect the overall pattern of results (Centanni et al., 2014c). Throughout the duration of the target speech sound / dad/, neurons in $\mathrm{DC}$ - rats fired more action potentials than control rats at the fastest two presentation rates (unpaired $t$ test, 10 sps: $p=$ $0.0005,20$ sps: $p=0.0001$ ) but were not different at the slower rates (all $p>0.13$ ). Similarly, peak latency in response to the target sound / dad/ differed across groups in only 2 of the presentation rates, such that $\mathrm{DC}$ - rats' neurons responded more quickly to the target than control neurons ( 2 sps: $p=0.008,10$ sps: $p=0.01$, all other rates: $p>0.08$ ). Because of the minimal basic firing differences to the target sound at various presentation rates, we investigated the differences in the speech signal across the tonotopic organization of A1 (Fig. 5). In response to rapidly presented speech sounds, the ED across sounds was not significantly different across untrained groups $(0.83 \pm 0.04$ in untrained $\mathrm{DC}-$ rats vs $0.83 \pm 0.06$ in untrained control rats; unpaired $t$ test, $p=0.32$ ). Variance in these two groups was also low: 0.008 in untrained DC - rats and 0.015 in untrained control rats.

We then used a different classifier (the continuous speech classifier; see Materials and Methods) that not only identified the onset of each sound in a sequence, but also identified the location of the target sound to evaluate the precision of speech stream encoding (Centanni et al., 2014c). There was no significant effect of group on classifier performance on sequences (repeatedmeasures ANOVA: $F_{(1,1)}=0.13, p=0.72$ ). Unpaired $t$ tests revealed that the classifier was significantly worse using activity from DC- compared with control A1 at only the fastest two presentation rates (Fig. 6A). At $10 \mathrm{sps}$, the classifier achieved $44.5 \pm 0.7 \%$ correct using control recordings versus $39.3 \pm 0.8 \%$
B

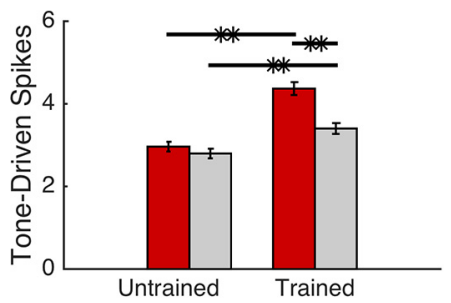

D

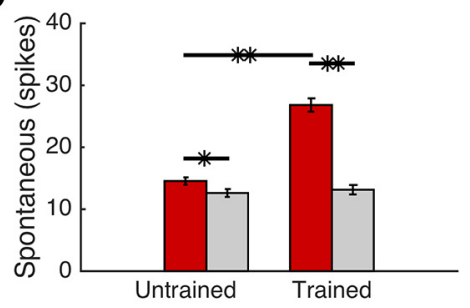

$\mathbf{F}$

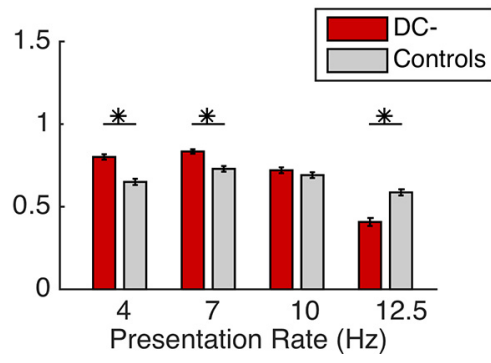

Figure 3. Summary of basic auditory firing differences in rats with $D c d c 2$ knockdown (DC - ). Error bars represent SEM. Tone and speech responses differed by group. Vector strength was calculated using the number of spikes evoked by bursts $2-6$

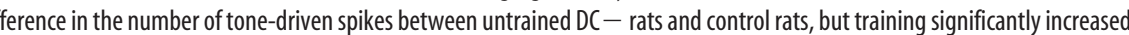

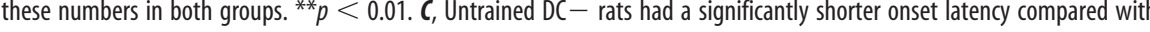
$D C$ - rats had a significantly higher vector strength compared with control rats at 3 of the 4 presentation rates tested.** $<0.01$. $\boldsymbol{F}$, Following training, $\mathrm{DC}$ - neurons had significantly higher vector strength compared with trained controls at 2 presentation rates but worse at the fastest rate. ${ }^{*} p<0.05$.

correct using DC - A1 recordings ( $p=0.001$ ); and at 20 sps, the classifier achieved $26.8 \pm 1.26 \%$ correct using control recordings versus $20.8 \pm 1.8 \%$ correct using $\mathrm{DC}-$ recordings $(p=0.01)$. Because the neural classifier was only impaired at the fastest rates but the animals were behaviorally impaired at all rates, the continuous speech classifier does not explain the degree of behavioral deficit observed in these animals. These results suggest that, before training, the level of excitability in the brains of rats with suppression of $D c d c 2$ is not enough to interfere with neural encoding of speech sounds at the primary sensory level.

\section{Extensive behavioral training alters neural responses}

Following behavioral training, all rats were anesthetized, and a total of 296 recording sites were acquired from A1. Compared with trained controls, A1 neurons of trained DC - rats had shorter onset latency $(18.11 \pm 0.70 \mathrm{~ms}$ in trained controls; unpaired $t$ test; $p=0.005)$, higher spontaneous firing rate $(13.15 \pm$ $0.76 \mathrm{~ms}$ in trained controls; unpaired $t$ test; $p=0.00001)$, and more driven spikes $(3.40 \pm 0.13$ spikes/tone in untrained DC-; unpaired $t$ test; $p=0.0001$; Fig. 3A-C; Table 1). Compared with untrained $\mathrm{DC}$ - rats, trained $\mathrm{DC}$ - rats had a shorter onset and peak latency (onset latency: $15.63 \pm 0.41 \mathrm{~ms}$ in trained DC - vs 
Table 1. Neural firing properties in A1 across all experimental groups

\begin{tabular}{lllllll}
\hline & $\begin{array}{l}\text { Threshold } \\
(\mathrm{dB})\end{array}$ & $\begin{array}{l}\text { Onset latency } \\
(\mathrm{ms})\end{array}$ & $\begin{array}{l}\text { Peak latency } \\
(\mathrm{ms})\end{array}$ & $\begin{array}{l}\text { BW20 } \\
\text { (octaves) }\end{array}$ & $\begin{array}{l}\text { BW40 } \\
\text { (octaves) }\end{array}$ & $\begin{array}{l}\text { Spontaneous } \\
\text { (spikes/s) }\end{array}$ \\
\hline Untrained controls & $7.24 \pm 0.61$ & $22.31 \pm 0.74$ & $23.35 \pm 0.51$ & $2.25 \pm 0.05$ & $3.22 \pm 0.06$ & $12.62 \pm 0.64$ \\
Untrained DC- & $7.09 \pm 0.58$ & $19.72 \pm 0.38$ & $22.54 \pm 0.57$ & $2.29 \pm 0.06$ & $3.24 \pm 0.07$ & $14.55 \pm 0.59$ \\
(spikes/stimulus)
\end{tabular}

Numbers are reported as mean \pm SEM.
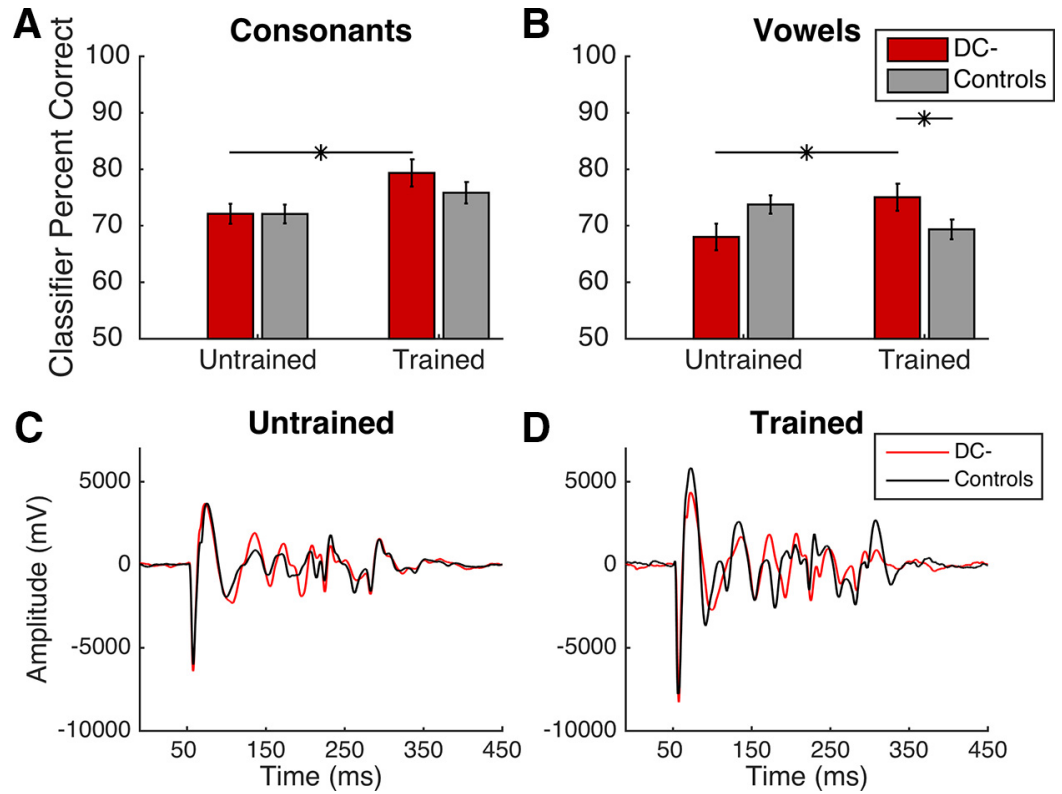

Figure 4. Effect of training on neural responses to and behavioral discrimination of speech sounds. Behavioral training improves precision of isolated, but not speech stream-evoked responses in $D C-$ brain. $A$, Before training, there were no significant differences in neural classifier performance using activity from $D C-A 1$ compared with control $A 1$. Following training, $D C-A 1$ was significantly better at precisely encoding consonant sounds, as measured by the classifier, compared with untrained $D C-$ $\left({ }^{*} p<0.05\right)$, and there was no significant change in controls. Chance performance for this task was $50 \%$. Error bars represent SEM. $B$, Before training, there was no difference in the classifier's overall ability to identify vowel sounds using activity from $D C$ - brains compared with control brains. Following training, $D C-A 1$ was significantly better at precisely encoding vowel sounds, as measured by the classifier, compared with untrained $D C-\left({ }^{*} p<0.05\right)$. Chance performance for this task was $50 \%$. C, Before training, there was no peak-to-peak difference in the LFP response across groups to the speech sound /dad/ (unpaired $t$ test; $p=0.59$ ). $\boldsymbol{D}$, After training, there were also no significant differences in the peak-to-peak LFP response to /dad/ (unpaired $t$ test; $p=0.45$ ).

$19.72 \pm 0.38 \mathrm{~ms}$ in untrained DC-; unpaired $t$ test; $p=0.0001$ and peak latency: $19.06 \pm 0.28 \mathrm{~ms}$ in trained $\mathrm{DC}-$ vs $22.54 \pm$ $0.57 \mathrm{~ms}$ in untrained DC - ; unpaired $t$ test; $p=0.0001$; Fig. $3 C$; Table 1). Training also caused higher spontaneous firing rates $(26.82 \pm 1.08$ spikes in trained DC - vs $14.55 \pm 0.59$ spikes in untrained DC - ; unpaired $t$ test; $p=0.0001$; Fig. $3 D)$, and more driven spikes ( $4.37 \pm 0.16$ spikes/tone in trained DC - vs $2.96 \pm$ 0.12 spikes/tone in untrained DC - ; unpaired $t$ test; $p=0.0001$; Fig. $3 A, B$; Table 1). These results suggest that training increases the level of excitability in the brains of DC - rats.

Our results confirm the earlier observation that neural plasticity is not specific to the trained speech sounds (C. T. Engineer et al., 2014b). Plasticity was also observed for nonspeech sounds. Vector strength was significantly greater in DC- brains compared with trained control brains on 2 of the 4 speeds tested ( $p=$ 0.0001; Fig. $3 F$ ). Training also increased the precision of consonant and vowel-evoked patterns in $\mathrm{A} 1$ of $\mathrm{DC}-$ rats. The isolated speech classifier was significantly better at identifying the evoking consonant stimulus using neural activity from the A1 of trained DC - rats compared with untrained DC - rats $(79.4 \pm 2.4 \%$ correct after training vs $72.1 \pm 1.8 \%$ correct before training, unpaired $t$ test, $p=0.02$; Fig. $4 A$ ) and was not significantly dif- ferent from trained controls (compared with $75.9 \pm 1.9 \%$ correct in trained controls, unpaired $t$ test, $p=0.24$; Fig. $4 A$ ). Trained DC - neural activity was significantly better at predicting vowel stimuli compared with neural activity from untrained DC $-(p=0.04)$ but was still worse than trained controls $(p<0.05$; Fig. $4 B$ ). Interestingly, training did not alter the peak-to-peak distance in the LFP response to isolated speech sounds (Fig. $4 D)$. Because the classifier relies on the presence of action potentials for its calculations, it was possible that increased excitability, caused by behavioral training, aided the isolated speech classifier and may do the same for the speech stream classifier.

However, despite training-related improvements to isolated speech classification, training caused a significant drop in performance in the continuous speech classifier at 4,5 , and 6.7 sps $(p=1.4 \mathrm{e}-4$; Fig. 6A). Because of difficulties during mapping, we were unable to acquire enough recordings to this stimulus set in control animals to evaluate the effect of training on the running speech classifier in controls (Centanni et al., 2014c). However, the neural responses to the target sound /dad/ are significantly stronger in trained DC- rats compared with both groups of untrained rats (Fig. $5 C$ ). In addition, although the variance in the Euclidean distance of DC- cortex in response to rapidly presented sounds following training was low (0.001), the ED values in this trained DC- group were significantly different from both untrained $\mathrm{DC}-$ rats $(0.77 \pm 0.05$; unpaired $t$ test vs untrained DC-, $p<0.001$ ) and untrained control rats (unpaired $t$ test; $p<0.001)$. These results suggest that increased neural excitability, brought on by training-induced neural plasticity, interferes with neural encoding of rapidly presented speech sound stimuli.

We calculated firing rate to series of broadband noise bursts, presented at four rates (Fig. 5B). Before training, there were no differences between control and $\mathrm{DC}-$ firing rates (two-way ANOVA; $\left.F_{(1,1)}=1.19, p=0.28\right)$. Following training, DC-A1 fired significantly more not only compared with untrained groups, but also compared with trained controls (repeatedmeasures ANOVA; $F_{(1,3)}=38.17, p=0.001$ ). Post hoc $t$ tests reveal that trained $\mathrm{DC}-\mathrm{A} 1$ fired significantly more than trained controls on 3 of the 4 speeds and more than both untrained groups at 3 of the 4 speeds (all $p$ values $<0.0001$ ). This dramatic increase in firing rates likely distorted the neural response to the 

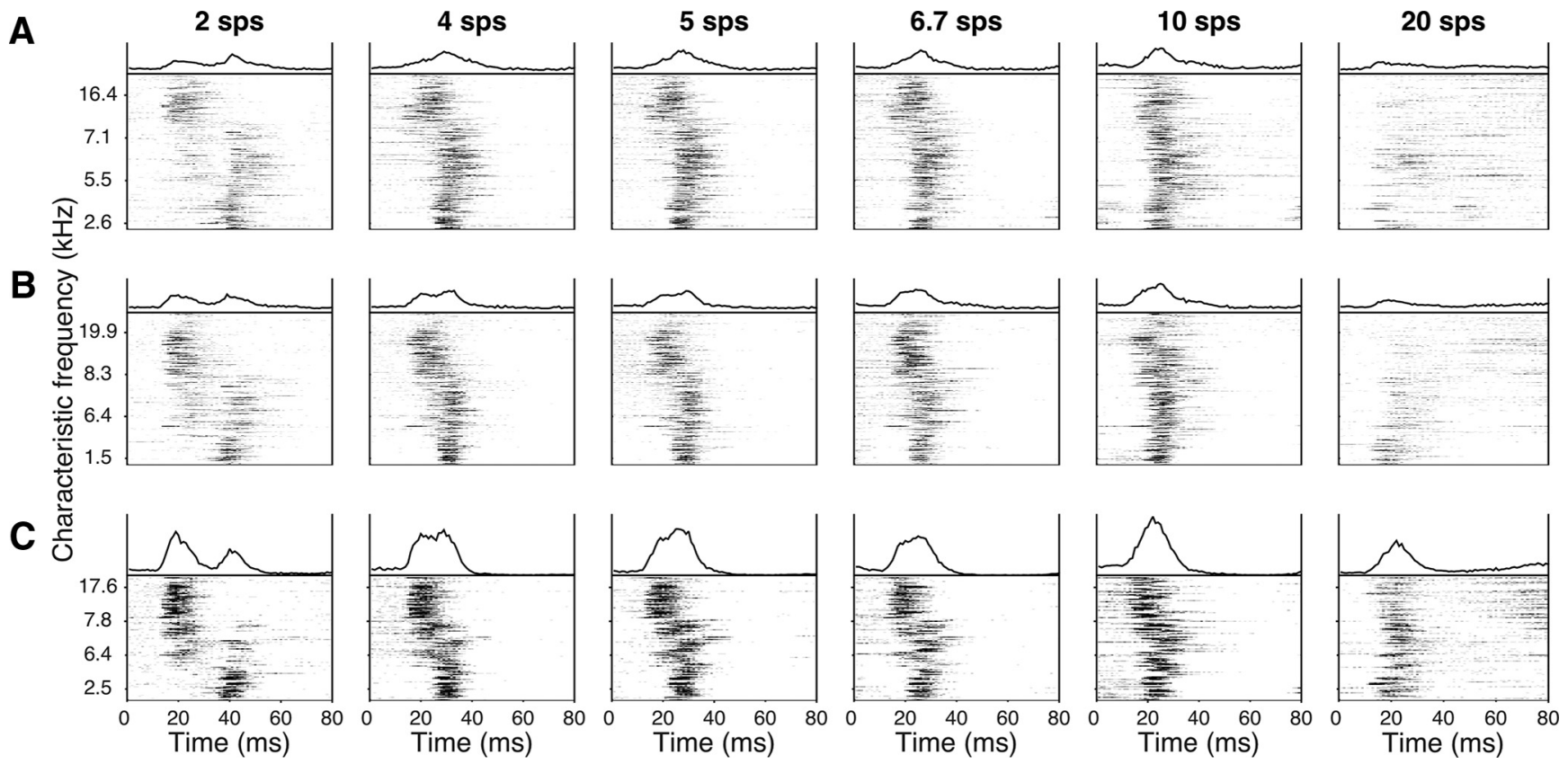

Figure 5. Control and DC - neural responses to speech stream stimuli. Rats heard the sequence/bad bad gad sad tad dad/ at 6 speeds:2,4,5,6.7, 10, and 20 syllables per second (sps). Average responses to the target sound /dad/ are displayed, organized by the characteristic frequency of the recording sites ( $y$-axis) and time ( $x$-axis). Left-most column, Slowest presentation rate. Right-most column, Fastest presentation rate. PSTH responses are plotted on top of each neurogram. $\boldsymbol{A}$, Responses from untrained control animals. $\boldsymbol{B}$, Responses from untrained DC - animals. C, Responses from trained DC - animals.
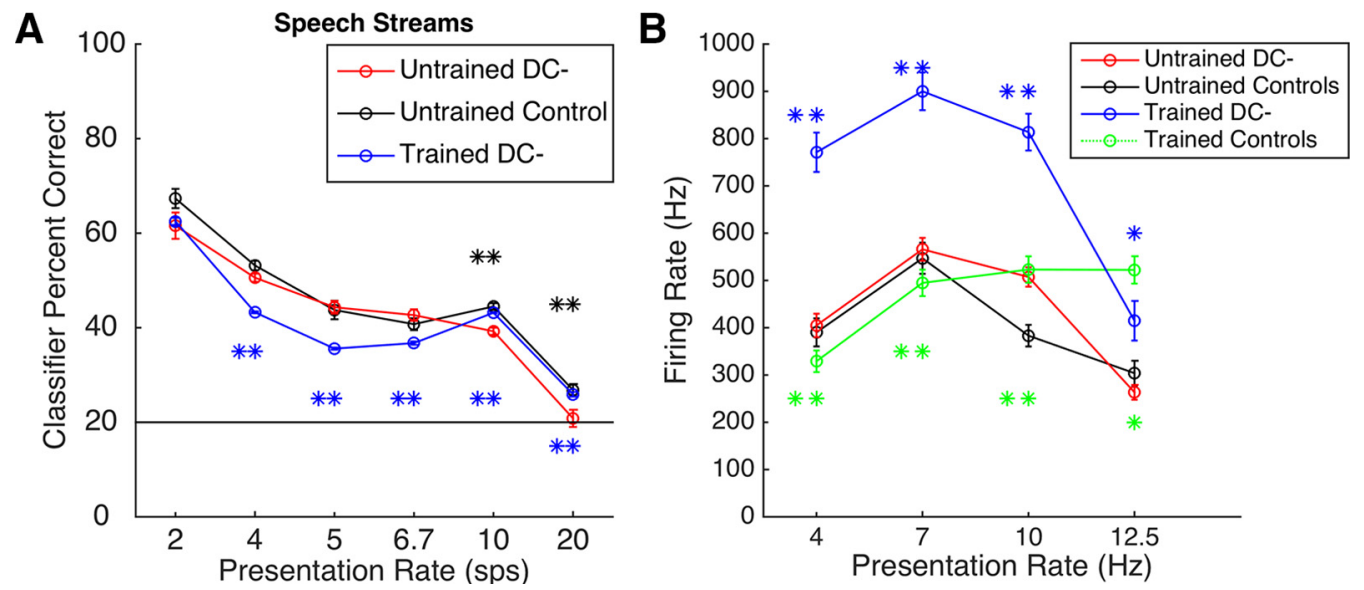

Figure 6. Neural classification results for speech sounds presented in a continuous stream using data from trained and untrained rats. Error bars represent SEM. $A$, Using a classifier that is able to determine target onset time from a stream of distractor sounds, performance was significantly worse using data from untrained DC $-A 1$ at the fastest 2 of the 6 presentation rates. ${ }^{* *} p<0.01$. Following training, $D C$ - neural responses were significantly worse than untrained $D C$ - recordings at 5 of the 6 presentation rates (all significant differences in blue). ${ }^{* *} p<0.01$. For this task, $20 \%$ was chance performance. $B$, Training increases $D C$ - neural firing rate to stimuli at a variety of speeds but does not affect control A1. Blue asterisks indicate significant difference between trained $D C-$ and all other groups. Green asterisks indicate significant difference between the two trained groups.

target sound and therefore caused a drop in classifier accuracy. Recent work in a rat model of Rett syndrome suggests that some genetic mutations may disrupt neural plasticity (C. T. Engineer et al., 2015). Typically, speech-sound behavioral training drives an increase in firing rates of $\mathrm{A} 1$ neurons tuned to low frequencies, as shown in the clustering of responses to low-frequency tones, shown in Figure 7A (red; Reed et al., 2011; Engineer et al., 2012). In our trained DC - rats, the intense firing to tones was localized to higher frequencies (Fig. $7 B$, red). In comparing the two groups, we observed a significant increase in neural firing in DC- neurons across the tonotopic distribution of $\mathrm{A} 1$, as demonstrated by the decreased response to low frequencies in blue and the increased response to higher frequencies in red (Fig. 7C). This re- sult suggests that suppression of $D c d c 2$ fundamentally alters the properties of training-induced neural plasticity.

\section{Discussion}

\section{Possible neural correlates of speech discrimination deficits}

Recent work has demonstrated the link between Kiaa0319 suppression on behavioral impairments in rats, including speech discrimination deficits (Szalkowski et al., 2012, 2013; Centanni et al., 2014a,b). Auditory cortex neurons in rats with Kiaa0319 suppression have increased variability when responding to tones and speech sounds and a decreased ability to synchronize firing to broadband noise bursts (Centanni et al., 2014a). This causes the 
A

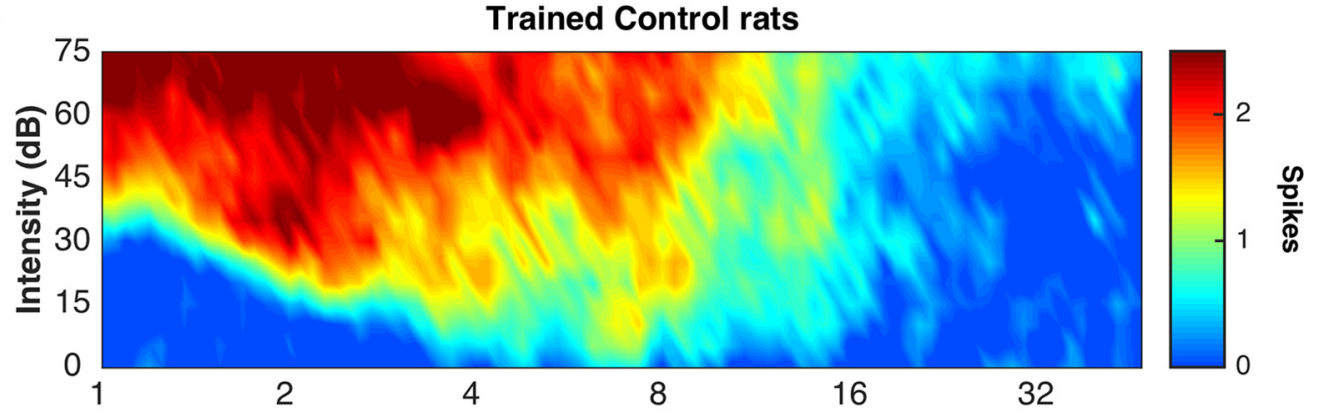

B

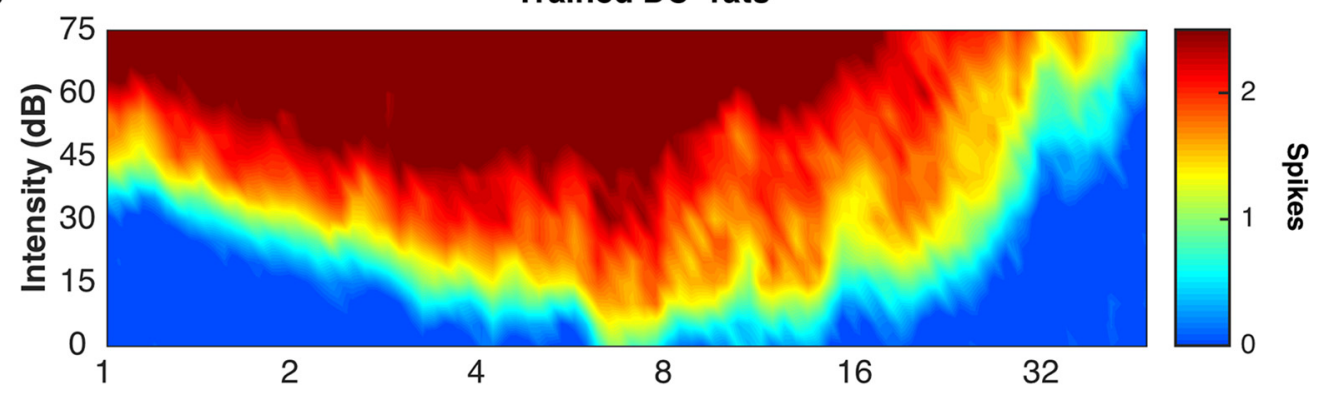

C

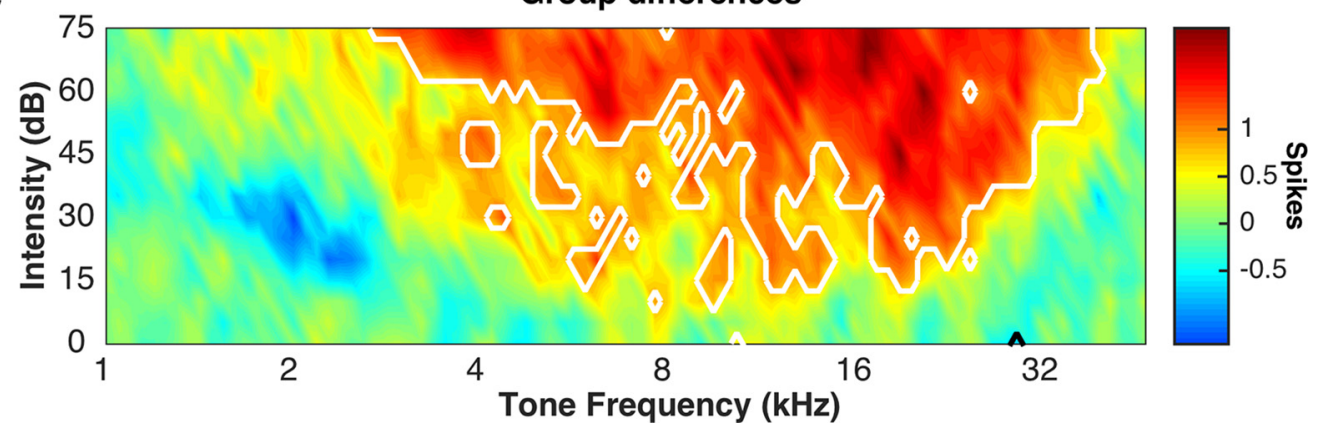

Figure 7. Effect of training on $A 1$ responses to tones in control and DC - rats. Training causes widespread hyperactivation of $A 1$ to tones in DC - rats. $A$, Following training, control rats showed high numbers of action potentials in response to tones $<4 \mathrm{kHz}$, which mimics the frequency range of the stimuli used in training. Red areas represent strong responses. Blue areas represent weaker responses. $\boldsymbol{B}$, Following training, $D C-$ rats $A 1$ responded strongly to tones $<16 \mathrm{kHz}$. Red areas represent strong responses. Blue areas represent weaker responses. $\boldsymbol{C}$, Tone-evoked spike counts are greater in trained DC - rats compared with controls. DC - rats were hyper-responsive to tones $>4 \mathrm{kHz}$ compared with control rats, which reflects a nonstimulus specific neural plasticity. Significant regions are outlined in white ( $p<0.05$, false discovery rate corrected for multiple comparisons).

typically clear and unique consonant-evoked patterns in A1 to be less temporally precise and therefore more difficult to distinguish from other consonant-evoked responses (C. T. Engineer et al., 2008; Centanni et al., 2013, 2014a). This lack of precision is likely due to an effect observed at the cellular level: neurons without the Kiaa0319 protein have increased membrane resistance and therefore fire significantly more action potentials to the same amount of current injection compared with various controls (Centanni et al., 2014a). This lack of millisecond temporal precision explains the difficulty of Kiaa0319 RNAi rats to discriminate short consonant stimuli, which themselves are only $40 \mathrm{~ms}$ long, and in the speech-in-noise condition, when the stimuli acoustics are degraded. In DC- animals, however, there was no onset-timing deficit in primary auditory cortex responses to rapid auditory stimuli and, indeed, no apparent degradation of the speechevoked response as a whole.

There are several possible reasons why our recordings did not demonstrate abnormal timing at the cellular level. First, previous patch-clamp experiments were conducted in cells with complete gene knock-out, whereas our cells experienced only suppression. In the knock-out, expression of Grin2B, which is a type of NMDA receptor, was causally related to timing precision and increased neural excitability (Che et al., 2014). It is possible that the animals in the current study were able to partially regulate these receptors with the amount of Dcdc2 protein available. Second, whereas previous work was conducted in a knock-out obtained through breeding, our study was conducted with genetic modification done surgically and in utero. We cannot rule out these possibilities, as mice do not have the behavioral control to train on our measures and the rat knock-out for this gene currently does not exist.

The extreme difficulty of DC- rats to perform the speech stream task, even at the slowest presentation rate ( $2 \mathrm{sps})$, is surprising, especially given the modest rapid speech response degradation in auditory cortex. Impaired processing speed is a common deficit in humans with dyslexia, as evidenced by poor performance on rapid automatized naming tasks (Norton and Wolf, 2012). A processing speed deficit would not be visible in A1 and would explain the pattern of results described here. Another possibility is that the suppression of $D c d c 2$ is either increasing hyperactivity or causing impairments in sustained attention in these animals, as this gene is linked to attention deficit hyperac- 
tivity disorder in humans (Scerri et al., 2011). The possibility of increased hyperactivity is less likely because only one-third of the conditions in one of the behavior tasks demonstrated increased reaction time in DC- animals, and decreased reaction time has been shown in humans with dyslexia during serial search tasks (Sireteanu et al., 2008; Vidyasagar and Pammer, 2010). The possibility of $D c d c 2$ suppression causing difficulties in sustained attention is supported by recent work demonstrating that knockout of $D c d c 2$ in mice causes persistent long-term memory deficits for visual stimuli (Gabel et al., 2011). Future work is needed to test these hypotheses and determine whether sustained attention deficits are responsible for the poor rapid speech sound discrimination deficits reported here. If our results hold, they suggest that suppression of $D c d c 2$ contributes to specific impairments in speech stream discrimination that are not explained by basic auditory processing.

\section{Altered neural plasticity and implications for intervention}

Not much is currently known about the role of dyslexia genes in neural plasticity. Speech training has been shown to drive specific changes in A1 based on task difficulty and stimulus characteristics (Reed et al., 2011; N. D. Engineer et al., 2012). Whereas rats with knockdown of Kiaa0319 displayed control-like neural responses following training, the current group of trained rats with knockdown of $D c d c 2$ instead showed decreased precision for speech sound responses and, as in the mouse model described above, increased firing rates.

Although there are a multitude of available interventions for dyslexia, none reports a $100 \%$ success rate. Recent neural imaging studies have attempted to investigate the basis for nonresponders with mixed results (Temple et al., 2003; Odegard et al., 2008; Richards and Berninger, 2008). Our observation that suppression of $D c d c 2$ alters the course of neural plasticity could be a possible explanation for some of these instances of failed intervention. In addition, the observed increase in neural excitability following training may be a mechanism for increased hyperexcitability in children with dyslexia. Future studies should investigate whether treatment nonresponders are also individuals with variants in DCDC2.

\section{Role of DCDC2 in the dyslexia phenotype}

The role of visual versus auditory deficits in dyslexia has been a long and ongoing debate in the field. Variants in the DCDC2 gene have been associated with a range of deficits. In humans, this gene has been linked to reading and vision specific traits (Lind et al., 2010; Cicchini et al., 2015; Gori et al., 2015), including the magnocellular system, which has been theorized to be deficient in dyslexia (Schulte-Körne and Bruder, 2010; Danelli et al., 2013; Gori et al., 2015). This gene has also been linked to deficits in visuo-spatial attention (Gori et al., 2015).

Because of the poor eyesight of albino rats, we were unable to test the visual acuity of our DC- rats to directly address this ongoing controversy. We therefore cannot be sure that this gene is not also affecting visual processing. However, because rats do not read, we can be relatively confident that any speech sound processing deficits we report here are due to auditory or higher cognitive processing differences and not due to the relationship between visual deficits and phonological awareness, as has been argued in humans (Reis and Castro-Caldas, 1997; Dehaene et al., 2010; Vidyasagar, 2013). A recent study demonstrated that the general pattern of phoneme-evoked activation, as measured by multivoxel pattern analysis in $\mathrm{fMRI}$, did not differ between typically developing individuals and those with dyslexia (Boets et al.,
2013; Ramus, 2014). Variants in this gene may therefore affect access to auditory representations, either instead of or in addition to altering the representations themselves by interfering with brain structure, specifically white matter tract integrity in left hemisphere temporoparietal areas (Paulesu et al., 1996; Swan and Goswami, 1997; Darki and Peyrard-Janvid, 2014).

One explanation is that the auditory system in children with dyslexia or specific language impairment is especially taxed by rapid stimulus presentation (Nagarajan et al., 1999; Benasich and Tallal, 2002; Wible et al., 2002), as we describe in the current study. Another possibility is that the brains of children with dyslexia are less able to keep their working memory for auditory stimuli up to date, especially when information must be quickly updated (Ahissar et al., 2006; Chandrasekaran et al., 2009). Increased neural excitability could also affect the transmission of information between brain regions. This result is compatible with either of the frameworks described above and would explain why performance fell dramatically in $\mathrm{DC}$ - rats when presentation rate increased.

\section{Limitations and future directions}

The main limitation in the current study is the sample size in the behaviorally trained group. Although only three DC- rats were tested, each of the animals performed significantly worse than controls, which suggests that this behavioral deficit is a consistent feature in rats with $D c d c 2$ suppression. Nevertheless, it is possible that, with a larger sample size, we may see some behavioral performance levels that are more similar to our previous work with Kiaa0319 knockdown rats. Therefore, the conclusion that these two genes result in different behavioral and neural profiles needs to be confirmed with larger sample sizes.

It is important to be cautious when interpreting results from studies in rodents in the context of a human disorder. Although rats show human-like levels of accuracy on speech sound discrimination tasks (C. T. Engineer at al., 2008; Shetake et al., 2011; Ranasinghe et al., 2012; Perez et al., 2013), these sounds are not ecologically relevant for rodents and the effect of these genes on phonological processing may differ in humans. Future work is needed to determine whether the unique profiles seen in rodents with either Kiaa0319 or Dcdc2 knockdown are similar to those seen in humans with variants in these same genes. To directly test the translational value of the results reported here, we are currently designing additional studies to investigate the hypothesis that the connection between $\mathrm{A} 1$ and other brain areas is impaired in dyslexia by evaluating speech stream processing using techniques in humans with better temporal precision than fMRI, such as MEG. The results of the current study demonstrate that variants in $D c d c 2$ impair auditory processing of speech stream stimuli in a different way than variants in another candidate gene, Kiaa0319, and provide one possible way the former gene may contribute to dyslexia in humans.

\section{References}

Ahissar E, Nagarajan S, Ahissar M, Protopapas A, Mahncke H, Merzenich MM (2001) Speech comprehension is correlated with temporal response patterns recorded from auditory cortex. Proc Natl Acad Sci U S A 98:13367-13372. CrossRef Medline

Ahissar M, Lubin Y, Putter-Katz H, Banai K (2006) Dyslexia and the failure to form a perceptual anchor. Nat Neurosci 9:1558-1564. CrossRef Medline

Bai J, Ramos RL, Ackman JB, Thomas AM, Lee RV, LoTurco JJ (2003) RNAi reveals doublecortin is required for radial migration in rat neocortex. Nat Neurosci 6:1277-1283. CrossRef Medline

Bai J, Ramos RL, Paramasivam M, Siddiqi F, Ackman JB, LoTurco JJ (2008) 
The role of DCX and LIS1 in migration through the lateral cortical stream of developing forebrain. Dev Neurosci 30:144-156. CrossRef Medline

Benasich AA, Tallal P (2002) Infant discrimination of rapid auditory cues predicts later language impairment. Behav Brain Res 136:31-49. CrossRef Medline

Boets B, Op de Beeck HP, Vandermosten M, Scott SK, Gillebert CR, Mantini D, Bulthé J, Sunaert S, Wouters J, Ghesquière P (2013) Intact but less accessible phonetic representations in adults with dyslexia. Science 342: 1251-1254. CrossRef Medline

Burbridge TJ, Wang Y, Volz AJ, Peschansky VJ, Lisann L, Galaburda AM, Lo Turco JJ, Rosen GD (2008) Postnatal analysis of the effect of embryonic knockdown and overexpression of candidate dyslexia susceptibility gene homolog Dcdc2 in the rat. Neuroscience 152:723-733. CrossRef Medline

Catts H, Adlof S, Hogan T, Weismer S (2005) Are specific language impairment and dyslexia distinct disorders? J Speech Lang Hear Res 48:13781396. CrossRef Medline

Centanni TM, Engineer CT, Kilgard MP (2013) Cortical speech-evoked response patterns in multiple auditory fields are correlated with behavioral discrimination ability. J Neurophysiol 110:177-189. CrossRef Medline

Centanni TM, Booker AB, Sloan AM, Chen F, Maher BJ, Carraway RS, Khodaparast N, Rennaker R, LoTurco JJ, Kilgard MP (2014a) Knockdown of the dyslexia-associated gene Kiaa0319 impairs temporal responses to speech stimuli in rat primary auditory cortex. Cereb Cortex 24:17531766. CrossRef Medline

Centanni TM, Chen F, Booker AM, Engineer CT, Sloan AM, Rennaker RL, LoTurco JJ, Kilgard MP (2014b) Speech sound processing deficits and training-induced neural plasticity in rats with dyslexia gene knockdown. PLoS One 9:e98439. CrossRef Medline

Centanni TM, Sloan AM, Reed AC, Engineer CT, Kilgard MP (2014c) Detection and identification of speech sounds using cortical activity patterns. Neuroscience 258:292-306. CrossRef Medline

Chandrasekaran B, Hornickel J, Skoe E, Nicol T, Kraus N (2009) Contextdependent encoding in the human auditory brainstem relates to hearing speech in noise: implications for developmental dyslexia. Neuron 64:311319. CrossRef Medline

Che A, Girgenti MJ, LoTurco J (2014) The dyslexia-associated gene Dcdc2 is required for spike-timing precision in mouse neocortex. Biol Psychiatry 76:387-396. CrossRef Medline

Cicchini GM, Marino C, Mascheretti S, Perani D, Morrone MC (2015) Strong motion deficits in dyslexia associated with DCDC2 gene alteration. J Neurosci 35:8059-8064. CrossRef Medline

Danelli L, Berlingeri M, Bottini G, Ferri F, Vacchi L, Sberna M, Paulesu E (2013) Neural intersections of the phonological, visual magnocellular and motor/cerebellar systems in normal readers: implications for imaging studies on dyslexia. Hum Brain Mapp 34:2669-2687. CrossRef Medline

Darki F, Peyrard-Janvid M (2014) DCDC2 polymorphism is associated with left temporoparietal gray and white matter structures during development. J Neurosci 34:14455-14462. CrossRef Medline

Davis N, Barquero L, Compton DL, Fuchs LS, Fuchs D, Gore JC, Anderson AW (2011) Functional correlates of children's responsiveness to intervention. Dev Neuropsychol 36:288-301. CrossRef Medline

DeFries JC, Fulker DW, LaBuda MC (1987) Evidence for a genetic aetiology in reading disability of twins. Nature 329:537-539. CrossRef Medline

Dehaene S, Pegado F, Braga LW, Ventura P, Nunes Filho G, Jobert A, Dehaene-Lambertz G, Kolinsky R, Morais J, Cohen L (2010) How learning to read changes the cortical networks for vision and language. Science 330:1359-1364. CrossRef Medline

Eckert M (2004) Neuroanatomical markers for dyslexia: a review of dyslexia structural imaging studies. Neuroscientist 10:362-371. CrossRef Medline

Engineer CT, Perez CA, Chen YH, Carraway RS, Reed AC, Shetake JA, Jakkamsetti V, Chang KQ, Kilgard MP (2008) Cortical activity patterns predict speech discrimination ability. Nat Neurosci 11:603-608. CrossRef Medline

Engineer CT, Centanni TM, Im KW, Borland MS, Moreno NA, Carraway RS, Wilson LG, Kilgard MP (2014a) Degraded auditory processing in a rat model of autism limits the speech representation in non-primary auditory cortex. Dev Neurobiol 74:972-986. CrossRef Medline

Engineer CT, Centanni TM, Im KW, Kilgard MP (2014b) Speech sound discrimination training improves auditory cortex responses in a rat model of autism. Front Syst Neurosci 8:137. CrossRef Medline

Engineer CT, Centanni TM, Im KW, Rahebi KC, Buell EP, Kilgard MP (2014c) Degraded speech sound processing in a rat model of fragile X syndrome. Brain Res 1564:72-84. CrossRef Medline

Engineer CT, Rahebi KC, Borland MS, Buell EP, Centanni TM, Fink MK, Im KW, Wilson LG, Kilgard MP (2015) Degraded neural and behavioral processing of speech sounds in a rat model of Rett syndrome. Neurobiol Dis 83:26-34. CrossRef Medline

Engineer ND, Engineer CT, Reed AC, Pandya PK, Jakkamsetti V, Moucha R, Kilgard MP (2012) Inverted-U function relating cortical plasticity and task difficulty. Neuroscience 205:81-90. CrossRef Medline

Farquharson K, Centanni TM, Franzluebbers CE, Hogan TP (2014) Phonological and lexical influences on phonological awareness in children with specific language impairment and dyslexia. Front Psychol 5:838. CrossRef Medline

Foffani G, Moxon KA (2004) PSTH-based classification of sensory stimuli using ensembles of single neurons. J Neurosci Methods 135:107-120. CrossRef Medline

Gabel LA, Marin I, LoTurco JJ, Che A, Murphy C, Manglani M, Kass S (2011) Mutation of the dyslexia-associated gene Dcdc2 impairs LTM and visuospatial performance in mice. Genes Brain Behav 10:868-875. CrossRef Medline

Galaburda AM, LoTurco J, Ramus F, Fitch RH, Rosen GD (2006) From genes to behavior in developmental dyslexia. Nat Neurosci 9:1213-1217. CrossRef Medline

Gori S, Mascheretti S, Giora E, Ronconi L, Ruffino M, Quadrelli E, Facoetti A, Marino C (2015) The DCDC2 intron 2 deletion impairs illusory motion perception unveiling the selective role of magnocellular-dorsal stream in reading (dis) ability. Cereb Cortex 25:1685-1695. CrossRef Medline

Green DM, Swets JA (1966) Signal detection theory and psychophysics. New York: Wiley.

Hornickel J, Kraus N (2013) Unstable representation of sound: a biological marker of dyslexia. J Neurosci 33:3500-3504. CrossRef Medline

Kawahara H (1997) Speech representation and transformation using adaptive interpolation of weighted spectrum: vocoder revisited. In: Acoustics, speech, and signal processing, Vol 2. 1997 IEEE International Conference, Munich, pp 1303-1306.

Lind PA, Luciano M, Wright MJ, Montgomery GW, Martin NG, Bates TC (2010) Dyslexia and DCDC2: normal variation in reading and spelling is associated with DCDC2 polymorphisms in an Australian population sample. Eur J Hum Genet 18:668-673. CrossRef Medline

Marino C, Meng H, Mascheretti S (2012) DCDC2 genetic variants and susceptibility to developmental dyslexia. Psychiatr Genet 22:25-30. CrossRef Medline

Nagarajan S, Mahncke H, Salz T, Tallal P, Roberts T, Merzenich MM (1999) Cortical auditory signal processing in poor readers. Proc Natl Acad Sci U S A 96:6483-6488. CrossRef Medline

Newbury DF, Paracchini S, Scerri TS, Winchester L, Addis L, Richardson AJ, Walter J, Stein JF, Talcott JB, Monaco AP (2011) Investigation of dyslexia and SLI risk variants in reading-and language-impaired subjects. Behav Genet 41:90-104. CrossRef Medline

Norton ES, Wolf M (2012) Rapid automatized naming (RAN) and reading fluency: implications for understanding and treatment of reading disabilities. Annu Rev Psychol 10:427-452. CrossRef Medline

Odegard TN, Ring J, Smith S, Biggan J, Black J (2008) Differentiating the neural response to intervention in children with developmental dyslexia. Ann Dyslexia 58:1-14. CrossRef Medline

Paulesu E, Frith U, Snowling M, Gallagher A, Morton J, Frackowiak RS, Frith CD (1996) Is developmental dyslexia a disconnection syndrome? Evidence from PET scanning. Brain 119:143-157. CrossRef Medline

Pennington BF, Gilger JW, Pauls D, Smith SA, Smith SD, DeFries JC (1991) Evidence for major gene transmission of developmental dyslexia. JAMA 266:1527-1534. CrossRef Medline

Perez CA, Engineer CT, Jakkamsetti V, Carraway RS, Perry MS, Kilgard MP (2013) Different timescales for the neural coding of consonant and vowel sounds. Cereb Cortex 23:670-683. CrossRef Medline

Peterson RL, Pennington BF (2012) Developmental dyslexia. Lancet 379: 1997-2007. CrossRef Medline

Pinel P, Fauchereau F, Moreno A, Barbot A, Lathrop M, Zelenika D, Le Bihan D, Poline JB, Bourgeron T, Dehaene S (2012) Genetic variants of FOXP2 and KIAA0319/TTRAP/THEM2 locus are associated with altered brain activation in distinct language-related regions. J Neurosci 32:817-825. CrossRef Medline

Polley DB, Read HL, Storace DA, Merzenich MM (2007) Multiparametric 
auditory receptive field organization across five cortical fields in the albino rat. J Neurophysiol 97:3621-3638. CrossRef Medline

Porter BA, Rosenthal TR, Ranasinghe KG, Kilgard MP (2011) Discrimination of brief speech sounds is impaired in rats with auditory cortex lesions. Behav Brain Res 219:68-74. CrossRef Medline

Ramus F (2014) Neuroimaging sheds new light on the phonological deficit in dyslexia. Trends Cogn Sci 18:274-275. CrossRef Medline

Ranasinghe KG, Vrana WA, Matney CJ, Kilgard MP (2012) Neural mechanisms supporting robust discrimination of spectrally and temporally degraded speech. J Assoc Res Otolaryngol 13:527-542. CrossRef Medline

Reed A, Riley J, Carraway R, Carrasco A, Perez C, Jakkamsetti V, Kilgard MP (2011) Cortical map plasticity improves learning but is not necessary for improved performance. Neuron 70:121-131. CrossRef Medline

Reed AC, Centanni TM, Borland MS, Matney CJ, Engineer CT, Kilgard MP (2014) Behavioral and neural discrimination of speech sounds after moderate or intense noise exposure in rats. Ear Hear 35:e248-e261. CrossRef Medline

Reis A, Castro-Caldas A (1997) Illiteracy: a cause for biased cognitive development. Int J Neuropsychol Soc 3:444-450. Medline

Richards TL, Berninger VW (2008) Abnormal fMRI connectivity in children with dyslexia during a phoneme task: before but not after treatment. J Neurolinguistics 21:294-304. CrossRef Medline

Scerri TS, Morris AP, Buckingham LL, Newbury DF, Miller LL, Monaco AP, Bishop DV, Paracchini S (2011) DCDC2, KIAA0319 and CMIP are associated with reading-related traits. Biol Psychiatry 70:237-245. CrossRef Medline

Schulte-Körne G (2010) The prevention, diagnosis, and treatment of dyslexia. Dtsch Arztebl Int 107:718-726; quiz 27. CrossRef Medline

Schulte-Körne G, Bruder J (2010) Clinical neurophysiology of visual and auditory processing in dyslexia: a review. Clin Neurophysiol 121:17941809. CrossRef Medline

Shaywitz SE (1998) Dyslexia. N Engl J Med 338:307-312. CrossRef Medline

Shetake JA, Wolf JT, Cheung RJ, Engineer CT, Ram SK, Kilgard MP (2011) Cortical activity patterns predict robust speech discrimination ability in noise. Eur J Neurosci 43:1823-1838. CrossRef Medline

Shetake JA, Engineer ND, Vrana WA, Wolf JT, Kilgard MP (2012) Pairing tone trains with vagus nerve stimulation induces temporal plasticity in auditory cortex. Exp Neurol 233:342-349. CrossRef Medline

Simos PG, Fletcher JM, Sarkari S, Billingsley RL, Denton C, Papanicolaou AC (2007) Altering the brain circuits for reading through intervention: a magnetic source imaging study. Neuropsychology 21:485-496. CrossRef Medline

Sireteanu R, Goebel C, Goertz R, Werner I, Nalewajko M, Thiel A (2008) Impaired serial visual search in children with developmental dyslexia. Ann N Y Acad Sci 1145:199-211. CrossRef Medline
Swan D, Goswami U (1997) Phonological awareness deficits in developmental dyslexia and the phonological representations hypothesis. J Exp Child Psychol 66:18-41. CrossRef Medline

Szalkowski CE, Fiondella CG, Galaburda AM, Rosen GD, LoTurco JJ, Fitch RH (2012) Neocortical disruption and behavioral impairments in rats following in utero RNAi of candidate dyslexia risk gene Kiaa0319. Int J Dev Neurosci 30:293-302. CrossRef Medline

Szalkowski CE, Fiondella CF, Truong DT, Rosen GD, LoTurco JJ, Fitch RH (2013) The effects of Kiaa0319 knockdown on cortical and subcortical anatomy in male rats. Int J Dev Neurosci 31:116-122. Medline

Temple E, Poldrack RA, Protopapas A, Nagarajan S, Salz T, Tallal P, Merzenich MM, Gabrieli JD (2000) Disruption of the neural response to rapid acoustic stimuli in dyslexia: evidence from functional MRI. Proc Natl Acad Sci U S A 97:13907-13912. CrossRef Medline

Temple E, Deutsch GK, Poldrack RA, Miller SL, Tallal P, Merzenich MM, Gabrieli JD (2003) Neural deficits in children with dyslexia ameliorated by behavioral remediation: evidence from functional MRI. Proc Natl Acad Sci U S A 100:2860-2865. CrossRef Medline

Threlkeld SW, McClure MM, Bai J, Wang Y, LoTurco JJ, Rosen GD, Fitch RH (2007) Developmental disruptions and behavioral impairments in rats following in utero RNAi of Dyx1c1. Brain Res Bull 71:508-514. CrossRef Medline

Truong DT, Che A, Rendall AR, Szalkowski CE, LoTurco JJ, Galaburda AM, Holly Fitch R (2014) Mutation of Dcdc2 in mice leads to impairments in auditory processing and memory ability. Genes Brain Behav 13:802-811. CrossRef Medline

Vandermosten M, Boets B, Luts H, Poelmans H, Golestani N, Wouters J, Ghesquière P (2010) Adults with dyslexia are impaired in categorizing speech and nonspeech sounds on the basis of temporal cues. Proc Natl Acad Sci U S A 107:10389-10394. CrossRef Medline

Vidyasagar TR (2013) Reading into neuronal oscillations in the visual system: implications for developmental dyslexia. Front Human Neurosci 7:811. CrossRef Medline

Vidyasagar TR, Pammer K (2010) Dyslexia: a deficit in bisuo-spatial attention, not in phonological processing. Trends Cogn Sci 14:57-63. CrossRef Medline

Wang Y, Yin X, Rosen G, Gabel L, Guadiana SM, Sarkisian MR, Galaburda AM, LoTurco JJ (2011) Dcdc2 knock-out mice display exacerbated developmental disruptions following knockdown of Dcx. Neuroscience 190: 398-408. CrossRef Medline

Wible B, Nicol T, Kraus N (2002) Abnormal neural encoding of repeated speech stimuli in noise in children with learning problems. Clin Neurophysiol 113:485-494. CrossRef Medline

Ziegler JC, Pech-Georgel C, George F, Lorenzi C (2009) Speech-perceptionin-noise deficits in dyslexia. Dev Sci 12:732-745. CrossRef Medline 